\title{
Land-use change and environmental sustainability
}

\author{
Ademola K. Braimoh • M. Osaki
}

Received: 15 August 2009/Accepted: 16 October 2009/Published online: 26 November 2009

(C) Integrated Research System for Sustainability Science, United Nations University, and Springer 2009

The concept of global environmental change evolved from concerns about the sustainability of the Earth, which is being transformed by human activities at an unprecedented scale and pace. United Nations (UN) world population data (http://www.un.org/esa/population) indicates that it took about 150 years (1750-1900) for the world's population to more than triple from 0.7 to about 2.5 billion, whereas it only took 40 years (1950-1990) for the population to double again to 5 billion. It is estimated that more than 1 billion people were added to the world's population between 1995 and 2008. The unprecedented growth in the human population in the last centuries translates to escalated resource consumption, as manifested in relatively high rates of agriculture and food production, industrial development, energy production and urbanization. These human enterprises lead to local land-use and land-cover changes that, when aggregated, have a global-scale impact on climate, hydrology, biogeochemistry, biodiversity and the ability of biological systems to support human needs (Foley et al. 2005; Sala et al. 2000).

Sustainability is the guiding principle for international environmental policy and decision-making in the twentyfirst century. It cuts across several international agenda, including the UN Framework Convention on Climate Change, the United Nations Convention to Combat Desertification, and the Convention on Biological Diversity, among others. The sustainability principle obscures

Edited by Mitsuru Osaki and Ademola Braimoh, Hokkaido University, Japan.

A. K. Braimoh $(\bowtie) \cdot$ M. Osaki

Center for Sustainability Science, Hokkaido University,

North 9 West 8, Kita-ku, Sapporo 060-0809, Japan

e-mail: abraimoh@glp.hokudai.ac.jp the distinction between environment and development and encourages the fusion of global change research and sustainable development (Turner 1997). There is a growing international community of researchers working on themes that are central to understanding land-use and land-cover change as a major driver of environmental change at local, regional and global scales. These scholars work within the interdisciplinary field of land-change science (LCS) - a scientific domain that seeks to understand the dynamics of the land system as a coupled human-environment system (CHES). A CHES is one in which the social and biophysical subsystems are so intertwined that the system's condition and responses to external forcing is based on the synergy of the two subsystems (Turner 2009). The Global Land Project, (GLP, http://www.globallandproject.org) jointly established by the International Human Dimensions Program on Global Environmental Change (IHDP, http://www.ihdp.org/) and the International Geosphere Biosphere Program (IGBP, http://www.igbp.net/) is the foremost international global change project promoting LCS for environmental sustainability. The GLP is planned around three research foci seeking to integrate a range of research questions towards an improved understanding of the dynamics of land change, the causes and consequences of land change, and assessment of system outcomes, notably vulnerability and resilience of land systems (GLP 2005; Turner et al. 2007). These GLP-related efforts focus on sustainability issues arising from changes and responses to the synergistic operations of societal and environmental subsystems of land. They provide an opportunity for international scholars with different disciplinary backgrounds to address these complex issues arising from human-environment interactions that cannot be satisfactorily dealt with by core disciplinary methods alone. 
This special feature documents progress in the fundamental components of LCS research. The issues addressed range from the sustainability of smallholder agriculture and urban systems to the impact of socioeconomic processes associated with globalization on biodiversity and ecosystem services supply. The first set of four papers exemplifies how models of varying complexities can be used to unravel the association between land-use and its spatial determinants. Yin and Xiang combine remote sensing data with social dataset to assess interactions between different facets of agricultural land-use and their determinants. By developing and estimating a structural model of land-use using spatially explicit longitudinal observations from the upper Yangtze basin of China, they demonstrate that technical change helps in supplying food where per-capita cropland is limited. Technical change also helps to reduce soil erosion, which then benefits grain production in the longer term.

The relationship between environmental loads (greenhouse gas emissions and farmland surplus nitrogen) and economic benefits (income from agricultural production) is addressed by Kimura et al. Eco-balance analysis for a watershed in Northern Japan showed that rice and soybean had high global warming potential (GWP), low farmland surplus nitrogen (FSN) and yields relatively high income. On the other hand, onion and vegetables had high FSN, low GWP and moderate income, whereas wheat showed negative GWP for some years, and abandoned land had a negative value. The study helps determine land-use combinations, where the iterative process always included wheat and some abandoned land, that strike a balance between increased farm incomes without increasing environmental load.

Using the Action-in-Context framework, $\mathrm{Wu}$ et al. developed a model to simulate future changes in sown areas of paddy rice in Asia given a set of alternative crops to land users and corresponding crop utility functions. Though some regions will experience a decrease in rice cultivated areas, the total rice-sown area in Asia in general was predicted by the model to increase from 124 million ha in 2005 to 144 million ha by 2035. According to $\mathrm{Wu}$ et al., the different patterns among Asian countries reflect variation in rice yield and price, which in turn influence its cultivation in different cropping systems. Adaptation options for regions where extreme events may amplify uncertainties in crop yields are suggested.

Using Northern Massachusetts as a case study, Pontius and Neeti compare two approaches to address the uncertainty in the maps produced by land change scenario models. One approach interprets the scenario storyline concerning the quantity of each land-change transition, and then considers the range of possibilities concerning the value added by a simulation model that specifies the spatial allocation of land change. The other approach estimates the uncertainty of future land maps based on a validation measurement with historic data. Results indicate that for the former, there is a bounded range for the difference between the raw scenario maps, whereas for the latter, uncertainties can be so great that the output maps do not show meaningful differences. Implications for land change modeling and management are discussed.

Two papers in this special feature address the sustainability of urban systems. The first paper by Fan and Qi developed an urban sustainability index comprising economic, environmental, and social factors. They further used this index to characterize the evolution of the cities of Urumqi and Guangzhou in China. The analysis highlighted fundamental socioeconomic driving forces that have caused spatial restructuring of these cities. The second paper on urban systems by Drechsel and Dongus applies the FAO framework for evaluating sustainable land management (FESLM) to assess the sustainability of urban agriculture in some African countries. They observe that whereas crop production in open space is largely marketdriven, the phenomenon is constrained principally by tenure insecurity and competition for non-agricultural uses. The viability of urban agriculture as a livelihood strategy prompts the authors to call for its institutional recognition and support so that environmental and health externalities associated with urban agriculture might be adequately addressed.

With globalization and increasing complexity in trade in biological resources, various issues pertaining to equity in transactions arise. Subramanian reviews the sustainability issues associated with the supply route and valueaddition chain of commercially exploited biodiversity resources. The results indicate that the complex sustainability issues connected to biodiversity business, coupled with inappropriate measures to address them, have enormous consequences for ecosystem services derived from biodiversity. The author concludes that sustainable use and management requires a complete rethinking of current production and consumption patterns, and a strong sociopolitical will for biodiversity conservation at different levels of governance.

The paper by Kasel et al. on drought frequency in Africa highlights the dependence of farmers in West Africa on rainfall, which has been fluctuating over the last few years, and how such variability affects food production in the Volta Basin. A historical analysis of drought events in the Basin indicated a 10-year drought recurrence. Regional drought analysis further reveals the temporal and spatial patterns of droughts. The analysis brings into relief the growing frequency of droughts since the 1980s, which, coupled with growing populations, has huge implications for food security in the region. 
The last paper by Rarieya and Fortun focuses on the mediating roles of institutions in land change processes. The authors first investigate the possible impacts of climate change on agriculture and food security in Western Kenya, and then outline possible uses of climate forecasts and related information to reduce human vulnerability. The arguments are built through a mix of literature reviews and primary research involving narratives from various stakeholders. To improve food security and environmental conservation, a conceptual framework termed 'agrocomplexity', which captures the major drivers of change and sustainable development, is introduced. The authors call for increased capacity building for institutions, communities and policymakers, along with improved lines of information dissemination to complement improved technologies for forecasting and adaptation.

The case studies presented in this special feature suggest significant prospects for land systems research. However, they also indicate that advancement in LCS in the coming years vis-à-vis realizing one or more unifying theories of land change that addresses the complexity of humanenvironment relationships will still depend on the level of cooperation amongst the relevant contributing core disciplines.

Acknowledgments This special feature is supported financially by MEXT through the Special Coordination Funds for Promoting
Science and Technology. We thank our team of reviewers for painstakingly carrying out manuscript evaluation. We also acknowledge the assistance of Kikuko Shoyama and Julius Agboola in preparing this special feature.

\section{References}

Foley JA, DeFries R, Asner GP, Barford C, Bonan G, Carpenter SR, Chapin FS, Coe MT, Daily GC, Gibbs HK, Helkowski JH, Holloway T, Howard EA, Kucharik CJ, Monfreda C, Patz JA, Prentice IC, Ramankutty N, Snyder PK (2005) Global consequences of land use. Science 309:570-574

GLP (2005) Global land project science plan and implementation strategy. IGBP Report No. 53/IHDP Report No. 19.64p

Sala OE, Chapin FS III, Armesto JJ, Berlow E, Bloomfield J, Dirzo R, Huber-Sanwald E, Huenneke LF, Jackson RB, Kinzig A, Leemans R, Lodge DM, Mooney HA, Oesterheld M, Poff NL, Sykes MT, Walker BH, Walker M, Wall DH (2000) Global biodiversity scenarios for the year 2100. Science 287(5459): 1770-1774

Turner BL II (1997) The sustainability principle in global agendas: implications for understanding land-use/cover change. Geogr $\mathbf{J}$ 163(2):133-140

Turner BL II (2009) Sustainability and forest transitions in the southern Yucatán: the land architecture approach. Land Use Policy (in press). doi:org/10.1016/j.landusepol.2009.03.006

Turner BL II, Lambin EF, Reenberg A (2007) The emergence of land change science for global environmental change and sustainability. Proc Natl Acad Sci 104(52):20666-20671 